\title{
OBSERVATIONS ON THE EXTRINSIC NERVOUS CONTROL OF THE AURICLES AND VENTRICLES IN COMPLETE AURICULO-VENTRICULAR BLOCK IN MAN
}

\author{
By ARTHUR C. DE GRAFF AND SOMA WEISS \\ (From the Department of Medicine, New York University Medical College; and \\ from the Second (Cornell) and the Third (N.Y.U.) Medical \\ Divisions of Bellevue Hospital)
}

(Received for publication August 17, 1925)

The influence of the extrinsic nerves of the heart on the sinoauricular node is well known (9a). In addition there is probably some direct effect on other areas in the heart. With an uninjured conducting system, however, there are obvious difficulties in finding out how much of the extrinsic nerve control is exerted on the auricles and how much on the ventricles. A study of the extrinsic nervous mechanism in complete auriculo-ventricular block is probably one of the best ways to attack this problem. Cullis and Tribe (2) working on the hearts of rabbits, found that after section of the auriculoventricular bundle, stimulation of the vagus produced no effect on the ventricles; whereas in the auricles the normal response was elicited. By the use of atropine and pilocarpine, they proved that no vagus fibres pass to the ventricles, and that the vagus effects in the intact heart were merely transmitted along the ordinary conduction paths. On the other hand, they found by direct stimulation of the sympathetic and the use of epinephrin that the ventricles have a rich sympathetic supply quite independent of the auricular innervation. In dogs, the evidence seems to point in the same direction. Wiggers and Katz (9b) found, by the use of epinephrin, that the accelerators have a specific effect on the ventricular musculature, reducing the contraction period. Eyster and Meek (3) were able to show, by paralyzing the vagus before and after excision of the sino-auricular node, that the greatest chronotropic effect of the vagus is upon the sino-auricular node.

In studies on man, recourse must obviously be had entirely to 
drugs. The literature on the subject consists mainly of reports of single cases, and the effect of the drug used, rather than the possible significance as to innervation. Thus Hardoy and Houssay (5), Strisower (8), and Feil (4) have reported that injections of epinephrin produce an increase in both the auricular and ventricular rates, in some cases the increase in ventricular rate exceeding by a considerable number of beats the increase in auricular rate. The vagal control has been studied by paralyzing the vagus endings with atropin. Apparently, then, the aim of previous investigations on the human subject was the study of the drug effects and their possibilities as therapeutic agents in heart block rather than the study of cardiac innervation. Therefore, we determined to investigate the nerve supply to the heart in a series of cases of complete heart block, using drugs only as a means for this end.

Eight cases of complete auriculo-ventricular block were selected from the wards of Bellevue Hospital. In order to study the sympathetic innervation varying doses of epinephrin were given to five patients and observations including clinical signs, blood pressures, and electrocardiograms were made. By giving 3 to $5 \mathrm{mg}$. of atropin sulphate the vagus endings can be paralyzed and results which are then free from any vagal influence can be noted. ${ }^{1}$ In four patients such an amount of atropine was given and observations similar to those mentioned above were made. We attempted to stimulate the vagus endings, in one instance, by a full body weight dose of digitalis. In order to see how much influence the vagus ordinarily exerted on the accelerator impulses, each of three patients was given an injection of epinephrin (which had previously produced certain effects) while the vagi were blocked by atropin.

The normal auricular and ventricular rates and blood pressures of eight cases of complete heart block are shown in table 1. The figures indicate the rate and blood pressures at the times when the patients were at rest. It is interesting to note that, as death ap-

'We are using the term "vagus" synonymously with "parasympathetic nerves." We realize that both the sympathetic nerve trunk to the heart and the vagus contain both sympathetic and parasympathetic types of nerve. Atropin paralyzes the parasympathetic endings both in the vagus and in the sympathetic trunk. 
proached, the ventricular rate in patient I dropped from 30 to 9 per minute, while in patient IV it rose from 34 to 84 per minute. The average age of the eight patients is 62 years, the maximum being 73 years and the minimum 49 years. The average ventricular rate is 31 per minute, the highest being 84 and the lowest 9 per minute. The average auricular rate is 79 , the highest being 93 and the lowest 62 per minute. The blood pressure ranged from a systolic pressure of $240 \mathrm{~mm}$. $\mathrm{Hg}$ to $124 \mathrm{~mm}$. $\mathrm{Hg}$ and a diastolic pressure of $90 \mathrm{~mm}$. $\mathrm{Hg}$ to $50 \mathrm{~mm}$. Hg, the average being a systolic pressure of 162 $\mathrm{mm} . \mathrm{Hg}$ and a diastolic pressure of $67 \mathrm{~mm}$. $\mathrm{Hg}$.

TABLE 1

Summary of cases

\begin{tabular}{|c|c|c|c|c|c|c|}
\hline \multirow{2}{*}{ CASE NUMBER } & \multirow{2}{*}{ AGE } & \multirow{2}{*}{ SEX } & \multirow{2}{*}{$\begin{array}{l}\text { AURICULAR } \\
\text { RATE }\end{array}$} & \multirow{2}{*}{$\begin{array}{l}\text { VENTRICULAR } \\
\text { RATE }\end{array}$} & \multicolumn{2}{|c|}{ BLOOD PRESSURE } \\
\hline & & & & & Systolic & Diastolic \\
\hline & & & & & $m m \cdot H g$ & $m m . H g$ \\
\hline 1 & 56 & M. & $65-88$ & $9-30$ & 240 & $80-90$ \\
\hline 2 & 69 & M. & 75 & 30 & 124 & 50 \\
\hline 3 & 73 & M. & 62 & 28 & 130 & 60 \\
\hline 4 & 58 & M. & 75 & $34-84$ & 124 & 50 \\
\hline 5 & 57 & M. & 64 & 34 & 162 & 68 \\
\hline 6 & 49 & F. & 72 & $31^{*}$ & 145 & 62 \\
\hline 7 & 68 & F. & 93 & 36 & 204 & 80 \\
\hline 8 & 70 & M. & 83 & 44 & 228 & 164 \\
\hline
\end{tabular}

* Total ventricular rate-includes four extrasystoles.

\section{EFFECT OF EPINEPHRIN}

Epinephrin was administered in doses varying from 1 to $2 \mathrm{mg}$. We avoided intravenous administration because of the fleeting action, accompanied by undesirable symptoms. Previous to the injection of the drug control electrocardiograms and blood pressure readings were made. Following the injection, tracings were taken at frequent intervals.

A summary of the findings in seven cases is recorded in table 2. The data indicate that subcutaneous doses of 1 to $2 \mathrm{mg}$. of epinephrin increase the auricular and ventricular rates considerably, an increase which is not always associated with a uniform rise in blood pressure. There is usually a greater change in the ventricular rate 
than in the auricular. On three occasions the rise in auricular rate was preceded by a moderate fall.

Figure 1 shows a typical effect of the injection of epinephrin. It can be noted that whereas the ventricular rate rises from 34 to 48 (a third over "normal") there is only a slight increase (68 to 70) in the auricular rate. Thus, in this instance, stimulation of the sympathetic causes the greater effect on the ventricles and very little effect on the auricles. This may be explained in one of two

TABLE 2

Summary of epinephrin effects

\begin{tabular}{|c|c|c|c|c|c|c|c|c|c|c|c|c|c|}
\hline \multirow{2}{*}{ 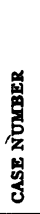 } & \multirow[b]{2}{*}{ 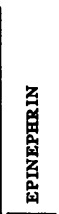 } & \multirow{2}{*}{ 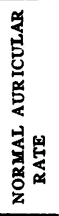 } & \multirow{2}{*}{ 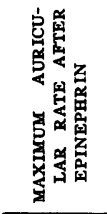 } & \multirow{2}{*}{ 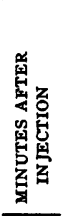 } & \multirow{2}{*}{ 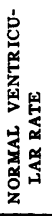 } & \multirow{2}{*}{ 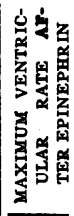 } & \multirow{2}{*}{ 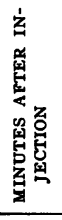 } & \multicolumn{2}{|c|}{$\begin{array}{c}\text { CONTROL } \\
\text { BLODD } \\
\text { PRESSURE }\end{array}$} & \multicolumn{2}{|c|}{$\begin{array}{c}\text { BLOOD PRESSURE, } \\
\text { MAXMMUM }\end{array}$} & \multirow{2}{*}{ 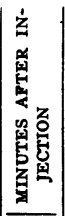 } & \multirow[b]{2}{*}{ 要 } \\
\hline & & & & & & & & 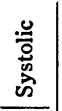 & 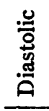 & 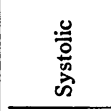 & 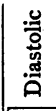 & & \\
\hline & $m g m$. & & & & & & & & & & & & \\
\hline 1 & 5.0 & 62 & 79 & 20 & 16 & 51 & 10 & - & - & - & - & - & \\
\hline 2 & 1.0 & 75 & 128 & 3 & 30 & 86 & 3 & 124 & 50 & 190 & 140 & 3 & \\
\hline 5 & 1.0 & 64 & 86 & 83 & 34 & 50 & 44 & 162 & 68 & 185 & 60 & 59 & \\
\hline 6 & 1.0 & 71 & No rise & - & 32 & 48 & 35 & 140 & 64 & No rise & & - & (1) \\
\hline 6 & 2.0 & 78 & No rise & - & 29 & 50 & 10 & 146 & 58 & 176 & 56 & 5 & (2) \\
\hline 7 & 1.5 & 91 & 132 & 15 & 36 & 66 & 15 & 204 & 80 & 230 & 75 & 25 & (3) \\
\hline
\end{tabular}

Remarks:

(1) Numerous ventricular premature contractions $10 \mathrm{~min}$. after injection which persisted for about one hour.

(2) Ventricular premature contractions more numerous. Persisted for almost three hours.

(3) Many ventricular premature contractions 5 min. after injection. Persisted for $35 \mathrm{~min}$.

ways: (1) The sympathetic supply to the auricles may be relatively less effective as compared to the ventricles; or (2) the vagus inhibition may be stronger in the auricles and so prevent full sympathetic action on them. To check this last possibility it is necessary to paralyze the vagus fibres completely and then to give epinephrin. Such a procedure was carried out and is reported under the heading, "Effect of epinephrin after paralysis of the vagi by atropine."

No significant changes in the length of the Q.R.S. interval in the electrocardiogram were noted after the administration of epinephrin, 
so it may be possible that conduction in the ventricle is unaltered after injection of epinephrin. The R.T. interval, however, was distinctly shortened. Our results do not permit us at present to make a definite statement in this regard and further work is being done on this aspect of the problem.

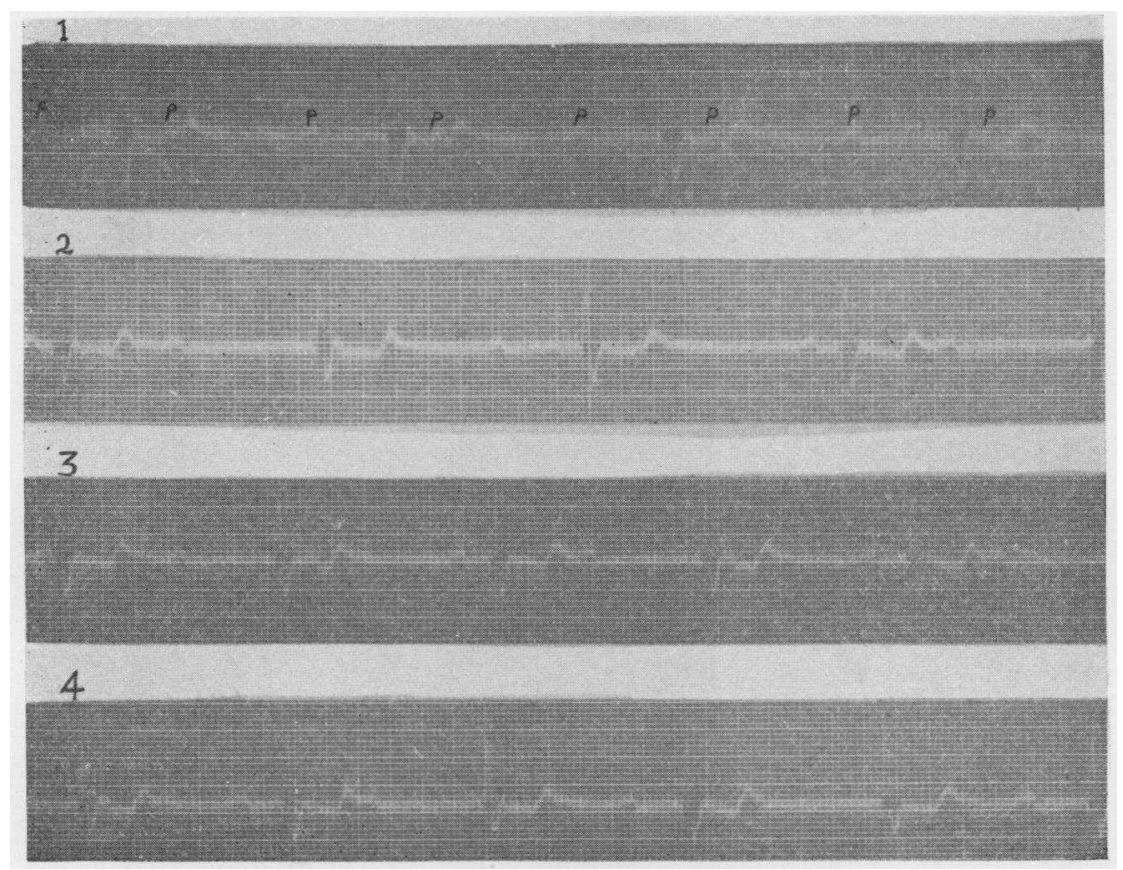

Fig. 1. Efrect of Epinephrin. Case 5

1, Control (normal). Lead II. 2, 4 minutes after injection of $1 \mathrm{mg}$. of epinephrin. 3, 10 minutes after injection of epinephrin. 4, 20 minutes after injection of epinephrin.

At no time did we succeed in changing complete block to a normal rhythm or to partial block.

In cases 6 and 7 there were, in the control records, occasional ventricular contractions, which did not occur in regular sequence with the dominant ventricular rhythm. Attempts were made to correlate these with auricular beats but such a correlation could never be shown to exist. We were therefore forced to assume that 
these contractions were ventricular premature beats arising from a second ventricular focus. After the injection of epinephrin, the number of these aberrant ventricular complexes increased, together with an augmentation in the complexes of the dominant rhythm. The increase in number of the ventricular ectopic beats suggests that epinephrin causes an increase of irritability in the ventricle.

Exact quantative measurements of changes in irritability and conductivity can be made only with difficulty in man, since mechanical as well as electrical events must be studied. Experimental work covering this point will be reported subsequently.

The data presented show, therefore, that the dominant effect of epinephrin is on the ventricle. Since epinephrin stimulates the sympathetic endings it seems reasonable to suppose that the sympathetic innervation of the ventricle is greater than that of the auricle.

TABLE 3

Summary of atropine effects

\begin{tabular}{|c|c|c|c|c|c|c|c|c|c|c|c|c|}
\hline \multirow{2}{*}{ 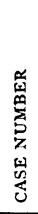 } & \multirow{2}{*}{ 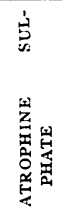 } & \multirow{2}{*}{ 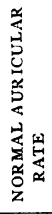 } & \multirow{2}{*}{ 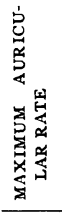 } & \multirow{2}{*}{ 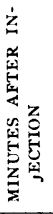 } & \multirow{2}{*}{ 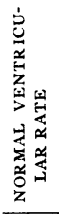 } & \multirow{2}{*}{ 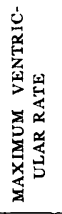 } & \multirow{2}{*}{ 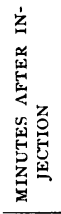 } & \multicolumn{2}{|c|}{$\begin{array}{c}\text { NORMAL } \\
\text { BLOOD } \\
\text { PRESSURE }\end{array}$} & \multicolumn{2}{|c|}{$\begin{array}{l}\text { BLOOD PRESSLRE AT } \\
\text { HEIGHT OF ACTION }\end{array}$} & $\underset{z}{z}$ \\
\hline & & & & & & & & $\begin{array}{l}\frac{y}{0} \\
\text { in } \\
\vec{n}\end{array}$ & 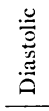 & 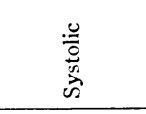 & 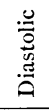 & 焉 \\
\hline & & & & & & & & & & & & \\
\hline 2 & 5.0 & 76 & 100 & 54 & 30 & 38 & 34 & 114 & 56 & Unchanged & & \\
\hline 5 & 5.0 & 70 & 100 & 15 & 34 & 38 & 15 & 190 & 60 & 140 & 70 & 65 \\
\hline 6 & 5.0 & 66 & 94 & 30 & 27 & 34 & 40 & 148 & 64 & Unchanged & & \\
\hline 7 & 3.5 & 98 & 118 & 10 & 34 & 36 & 10 & 205 & 78 & Unchanged & & \\
\hline
\end{tabular}

EFFECT OF ATROPINE

We administered $5.0 \mathrm{mg}$. of atropine sulphate in four cases and $3.5 \mathrm{mg}$. in another. The results of our observations are summarized in table 3. An analysis of the data indicates that, following the injection of doses of atropine sufficiently large to completely paralyze the vagus endings, the auricular rate increased by an average of twenty five beats per minute. The rise in auricular rate is practically the same as Crawford (1) found in normal individuals after paralysis of the vagi. This would indicate that the influence of the vagus on the sinus node is the same in the cases of complete heart 
block studied as in normal persons. There is also a slight but distinct increase in the ventricular rate. However, we found slight variations in the ventricular rate in these patients from time to time before the drug was given. Since the increase in ventricular beats after atropine is within these control limits it is possible. that we are still dealing with these slight variations even after paralysis of the vagi. Yet, the change in rate after atropine is always in the same direction, i.e., upward, and it may be that the change in rate is an atropine effect. It is possible, then, that the ventricle has a few vagus fibres which functionate even though conduction from auricle to ventricle is completely blocked. In any case, the vagus effect on the ventricle is so very slight that it can be regarded as negligible.

EFFECT OF EPINEPHRIN FOLLOWING THE PARALYSIS OF THE VAGI BY ATROPINE

We have shown above that epinephrin in small doses produces but a slight rise in the auricular rate, while the ventricular rate is markedly increased. In fact, in case 6 , a dose was found which produced a moderate increase in the ventricular rate and practically no change in the auricular rate. Furthermore, from observations on the effect of atropine we were led to believe that in complete block the direct influence of the vagi on the ventricles is slight. If this is correct, one would expect that if a dose of epinephrin, such as would not produce a change in auricular rate, be administered when the vagi have been paralyzed with atropine, both the auricles and the ventricles would respond with an increase, but the increase in ventricular rate would be only slightly greater than if epinephrin had been administered alone. 'Observations have demonstrated the correctness of this assumption in two instances (cases 6 and 7). In both cases epinephrin was administered at the time when the full effect of atropine had developed. In both patients the auricles responded with a marked rise. The increase in ventricular rate was practically the same as in the two control observations where epinephrin was administered alone. These facts are illustrated in Table 4 which shows the comparative effects of paralysis of the vagi and stimulation of the sympathetic in patient 6 . When atropine alone was given, the maximum auricular rate was 94 beats per minute, thirty 
minutes after injection. Thus it is evident that in table $4(C)$ epinephrin was given at the height of the atropine action.

These patients were all over 40 years of age, and it might be said that their vagus tone had diminished to such an extent that blocking the fibres with atropine had no effect. The increase in auricular rate noted above when atropine was administered is evidence that such was not the case.

TABLE 4

Effect of the administration of epinephrin after paralysis of the vagi by atropine (case 6)

\begin{tabular}{|c|c|c|c|c|}
\hline TIME IN MINUTES & AURICULAR RATE & VENTRICULAR RATE & $\begin{array}{c}\text { PREMATURE } \\
\text { VENTR ICULAR } \\
\text { CONTRACTIONS } \\
\text { PER MINUTE }\end{array}$ & $\begin{array}{c}\text { TOTAL } \\
\text { VENTR ICULAR RATE }\end{array}$ \\
\hline
\end{tabular}

A. Effect of atropine

\begin{tabular}{|c|c|c|c|c|}
\hline & 66 & 24 & 3 & 27 \\
\hline & \multicolumn{4}{|c|}{ Atropine sulphate $5.0 \mathrm{mgm}$. injected subcutaneously } \\
\hline 10 & 80 & 28 & 0 & 28 \\
\hline 17 & 91 & 29 & 0 & 29 \\
\hline 20 & 91 & 28 & 0 & 28 \\
\hline 30 & 94 & 28 & 0 & 28 \\
\hline 40 & 93 & 26 & 8 & 34 \\
\hline 50 & 93 & 27 & 2 & 29 \\
\hline 60 & 88 & 25 & 5 & 30 \\
\hline 80 & 82 & 26 & 1 & 27 \\
\hline 90 & 82 & 26 & 0 & 26 \\
\hline 100 & 82 & 27 & 2 & 29 \\
\hline 120 & 80 & 27 & 0 & 27 \\
\hline
\end{tabular}

B. Effect of epinephrin

\begin{tabular}{|c|c|c|c|c|}
\hline & $\begin{array}{l}72 \\
71\end{array}$ & $\begin{array}{l}27 \\
26\end{array}$ & $\begin{array}{l}4 \\
4\end{array}$ & $\begin{array}{l}31 \\
30\end{array}$ \\
\hline & \multicolumn{4}{|c|}{ Epinephrin $1 \mathrm{mgm}$. (1: 1,000) injected subcutaneously } \\
\hline 2 & 68 & 25 & 8 & 33 \\
\hline 3 & 68 & 26 & 8 & 34 \\
\hline 4 & 68 & 28 & 7 & 35 \\
\hline 5 & 72 & 30 & 2 & 32 \\
\hline 10 & 69 & 28 & 17 & 45 \\
\hline 20 & 67 & 28 & 15 & 43 \\
\hline 30 & 67 & 28 & 12 & 40 \\
\hline 35 & 72 & 24 & 24 & 48 \\
\hline 45 & 74 & 28 & 17 & 45 \\
\hline 55 & 71 & 28 & 8 & 36 \\
\hline 65 & 71 & 27 & 15 & 42 \\
\hline
\end{tabular}




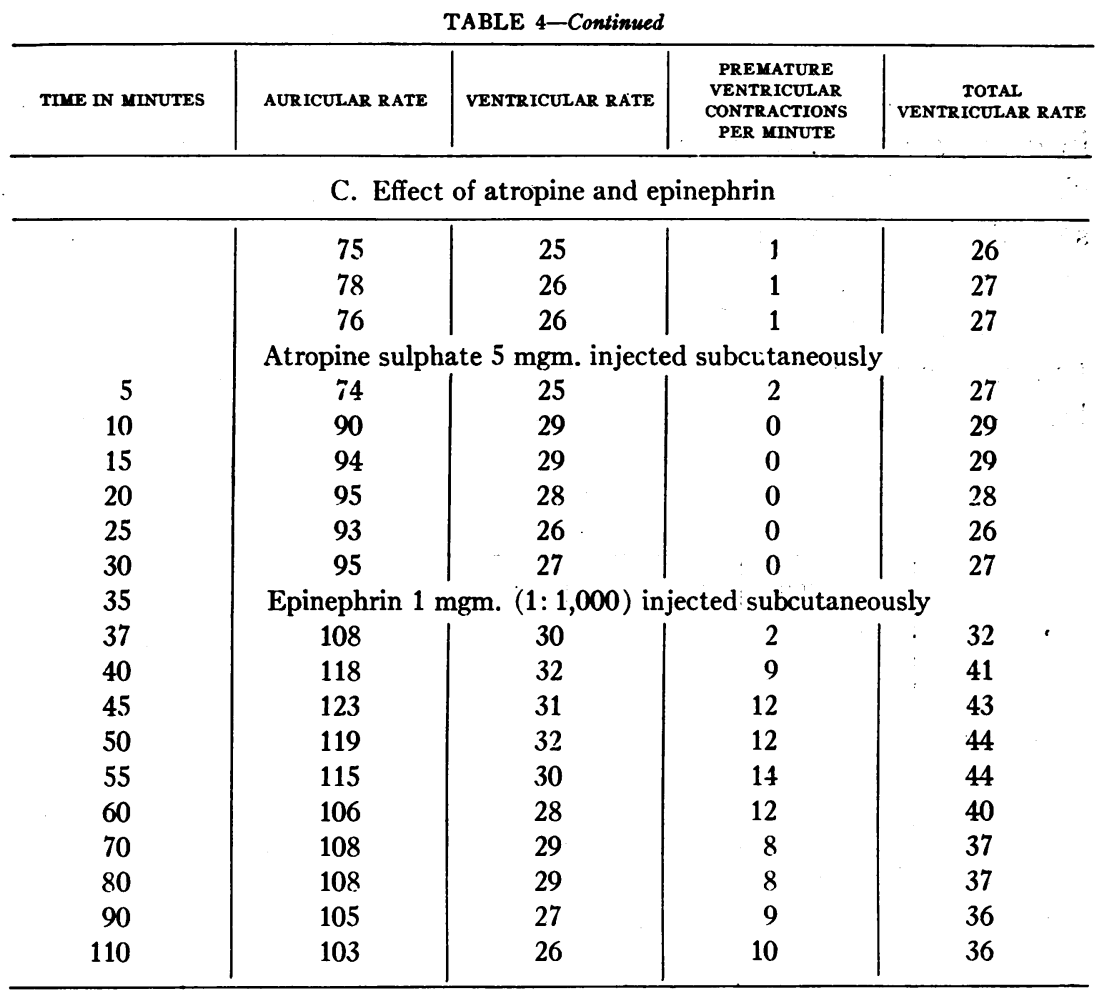

The evidence, then, indicates that the experimental results of Cullis and Tribe are in the main applicable to man.

\section{EFFECTS OF DIGITALIS}

In other forms of cardiac irregularities, digitalis has been used to stimulate the vagus endings, particularly in reference to the auricles. With this in mind, a full body-weight dose of a standardized tincture of digitalis was given to patient 6 . Frequent clinical observations were made and many electrocardiograms taken during the next twenty-four hours. No change in the auricular or ventricular rates occurred, although the patient was completely digitalized as evidenced by the slight nausea of which she complained and the inversion of the $\mathrm{T}$ wave in Lead II of the electrocardiogram. 


\section{EFFECT OF EXERCISE}

Many observations have been made in the past showing that in complete block there is no rise in the ventricular rate after exercise. In order to make this study as complete as possible, we observed the effects of exercise in our patients. Two instances are reported below.

Patient 6 exercised by bending the knees and body twenty-five times. As shown in table 5, there is an immediate rise in the auricular rate, about the same as one would expect in a normal individual,

TABLE 5

Effect of exercise (case 6)

\begin{tabular}{|c|c|c|c|c|c|c|}
\hline TMEE & $\underset{\text { RATE }}{\text { AORICUAR }}$ & $\begin{array}{l}\text { VENTRICULAR } \\
\text { RATE }\end{array}$ & $\begin{array}{l}\text { PREMATURE } \\
\text { VENTICUARR } \\
\text { CONTRACTION }\end{array}$ & $\begin{array}{l}\text { TOTAL } \\
\text { VENTRIITELAR } \\
\text { RATE }\end{array}$ & \multicolumn{2}{|c|}{ BLOOD PRESSURE } \\
\hline 11.35 & 78 & 26 & 2 & 28 & 130 & 62 \\
\hline 11.40 & 76 & 25 & 2 & 27 & 134 & 60 \\
\hline \multicolumn{7}{|c|}{ 11.46-47 Exercise-25 Knee-bends } \\
\hline 11.48 & 104 & 23 & .7 & 30 & & \\
\hline 11.52 & 82 & 20 & 10 & 30 & 145 & 64 \\
\hline 11.55 & 81 & 19 & 11 & 30 & 135 & 62 \\
\hline 12.00 & 85 & 27 & 7 & 34 & & \\
\hline 12.05 & 81 & 28 & 4 & 32 & & \\
\hline $12.13-1$ & \multicolumn{6}{|c|}{ Exercise-25 Knee-bends } \\
\hline 12.15 & 108 & 21 & 7 & 28 & 150 & 62 \\
\hline 12.20 & 94 & 27 & 5 & 32 & & \\
\hline 12.25 & 92 & 27 & 8 & 35 & 130 & 64 \\
\hline 12.30 & 96 & 29 & 5 & 34 & & \\
\hline
\end{tabular}

but no change in the ventricular rate. Patient 4 , on his first admission, when at rest, showed an occasional dropped ventricular beat without an increased P-R interval as his only evidence of interference in conductivity between auricles and ventricles. Upon moderate exercise (bending the body backward and forward about twenty times) his rhythm, as shown by the electrocardiograms, changed to a complete heart block with long periods of asystole. Such a change from a partial to a complete block on exercise has also been noted by Sands (7). 


\section{EFFECT OF CHEYNE-STOKES RESPIRATION}

The frequent association of Cheyne-Stokes breathing with complete heart block has been noted by a number of observers who apparently observed no abnormal changes in heart rate with different phases of respiration. In 1913 Oppenheimer and Williams (6) reported a case of complete a-v block with Cheyne-Stokes respiration in which, during the dyspneic period, the auricular rate was strikingly reduced as compared with the period of apnea. The ventricular rate, however, was only slightly lowered during dyspnea. The explanation offered was that the vagus in complete heart block retained a marked chronotropic effect on the auricle and little, if any, on the ventricle. This explanation is in accord with the conclusions which we drew from the epinephrin and atropine experiments. However, in our series, patient 3 showed a marked slowing of ventricular rate at the beginning of the hyperpneic period and an increase in ventricular rate during the apneic period. The auricular rate was unchanged throughout. In the light of all previous work this could not be a vagal effect. It is possible that, in this instance, the anoxemia resulting from the apnea affects the ventricular muscle directly. In two other patients with Cheyne-Stokes breathing no auricular or ventricular rate changes were noted which could be correlated with respiratory phases.

At least three conditions may therefore occur during CheyneStokes breathing in complete block, as shown by these and other cases reported in the literature.

1. No change in the auricular or ventricular rates.

2. A marked slowing of the auricular rate during the dyspneic period and a corresponding rise during apnea; but very little change in the ventricular rate.

3. A marked slowing of the ventricular rate during the dyspneic periods and a corresponding rise during apnea; but no change in the auricular rate.

\section{VARIATIONS IN AURICULAR AND VENTRICULAR COMPLEXES}

In the course of this work our attention was directed to the frequency with which variations in auricular and ventricular complexes 
of the electrocardiograms were encountered. The drug employed, the dosage, and the time of injection seemed in most instances to bear no relation to the occurrence of these abnormalities; in fact they were frequently present in the control tracings. Possibly the same factors which produced the complete block are operative here. Some

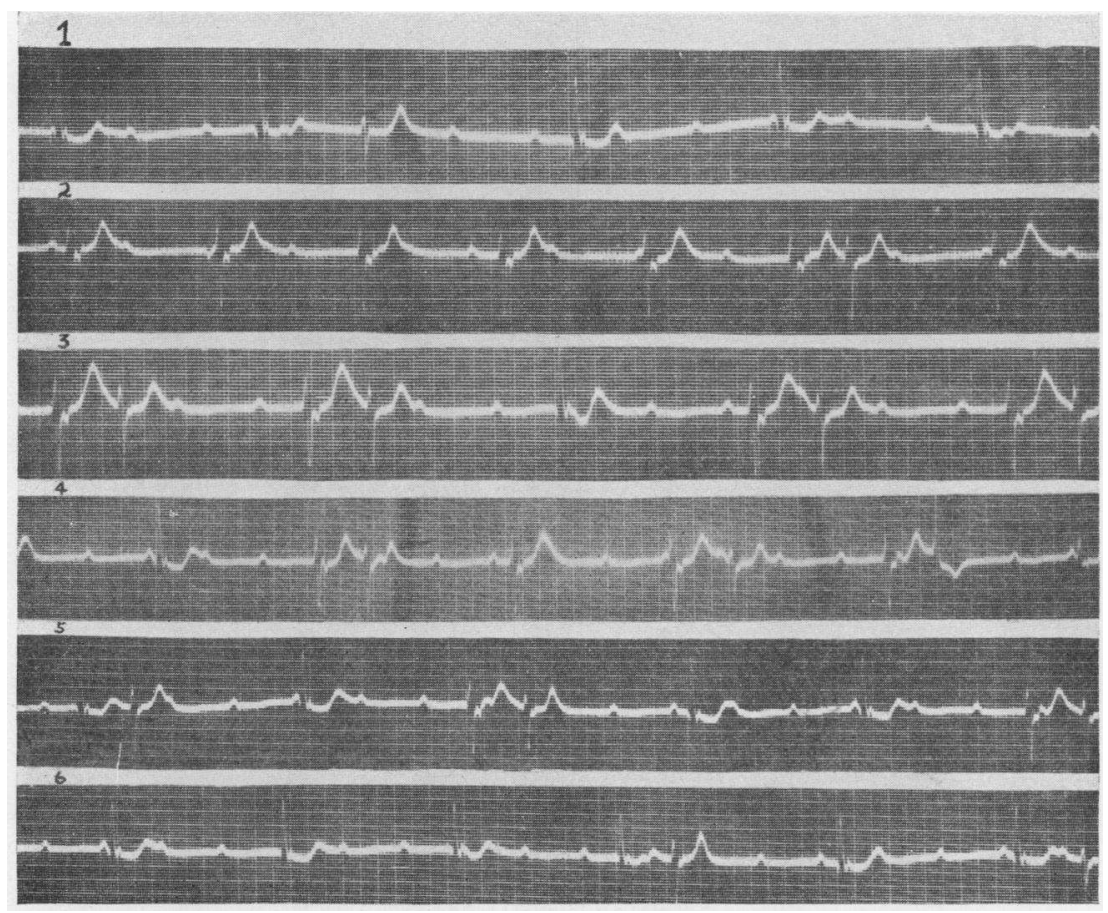

Fig. 2. Effect of Epinephrin upon the Ventricllar Complexes. Case 6

1 , control electrocardiogram. 2, electrocardiogram at height of epinephrin effect. $3,4,5,6$, successive steps in return to normal.

of the abnormalities of the $\mathrm{P}$ wave noted were inversion, dropping and irregular spacing.

Two cases showed intraventricular block in addition to their a-v block. Two cases presented ventricular premature contractions of reversed electrical potential from the dominant ventricular potential. No regularity in the occurrence of these beats was noted although particular attention was paid to it, several five minute tracings having 
been taken and carefully counted. The ventiicular premature contractions in these cases apparently came from a focus fairly high in the conducting system because the $R$ bases throughout were less than 0.10 second.

In case 6 , the ventricular premature complexes were in the opposite direction to the normal dominant ventricular complexes. Fifteen minutes after the injection of epinephrin (on two occasions) the direction of all the complexes was that of the premature contractions (tracing 3, fig. 2). Accompanying these changes there was considerable precordial pain. The ventricular complexes returned to the original type 165 minutes after the injection of epinephrin.

Three possible explanations may be presented.

1. That epinephrin during the height of its activity changed the electrical axis of the heart.

2. That, with the increase in irritability of the ventricular musculature after the administration of epinephrin, the focus which had previously been responsible for only an occasional ventricular premature systole, now became the dominant pacemaker of the ventricle, and that as the effect of the epinephrin wore off the original pacemaker gradually assumed control again.

3. That epinephrin produced a change in conduction. None of these theories satisfactorily explain tracing 3 . Although in tracing: two, all the complexes have the same direction, yet the rhythm is not regular and complexes are present which appear to be premature in relation to other complexes just as was the case before epinephrin was given. It we are to conceive of all the ventricular complexes in tracing two as coming from one focus, then we would have to assume a varying irritability. It is even more difficult to think of a change in the electrical axis where the reversion back to normal is accomplished by a gradual increase of normally directed complexes as the effect of the drug wears $\backslash f f$. If the explanation were an alteration of ventricular conductivity as a whole one might expect variations in the duration of the Q.R.S. group. These are not apparent.

\section{SUMMARY}

An effort was made to study the extrinsic nervous control of the auricles and ventricles in the human heart. Eight cases of complete 
heart block were studied with epinephrin, atropine, and digitalis. Observations were also made as to the effect of Cheyne-Stokes respiration and exercise.

Subcutaneous injections of epinephrin in doses varying from 1 to $5 \mathrm{mg}$. were given in seven cases. A considerable rise in ventricular rate always occurred and usually a rise in auricular rate, which, however, was not as great. The blood pressure usually rose but in one case the rise was transient and was followed by a fall. In two instances the rise in ventricular rate was associated with the appearance of numerous ventricular premature contractions probably from some focus other than the one originating the dominant rhythm. Since it is generally assumed that the effect of epinephrin on the heart is similar to a stimulation of the sympathetic endings, we have indications from these observations that the sympathetic control of the ventricles is more pronounced than that of the auricles.

Atropine sulphate in doses sufficient to paralyze the vagus endings was administered in four cases. The auricular rate increased by an average of 25 beats per minute, an increase which agrees with the rise of 23 beats per minute found by Crawford in normal individuals after paralysis of the vagi. This would indicate that the influence of the vagus on the sinus node is the same in the cases of complete block studied as in normal persons. A slight but distinct rise in ventricular rate occurred in each instance, indicating that the vagi exert a slight inhibiting effect on the ventricle in complete block.

When epinephrin was injected after the vagi had been paralyzed with atropine, although the auricular rate rose considerably, the ventricular rate increased only very little. It is evident, therefore, that the vagal influence on the ventricles is slight while the sympathetic control is considerable.

Digitalis in one patient caused no variations in auricular or ventricular rates although there was full digitalization as evidenced by the slight nausea and the inverted $\mathrm{T}$ wave in the lead of the electrocardiogram.

The cases in which the effect of exercise was noted presented the usual findings, a rise in auricular rate, but no change in the ventricular, rate.

Three patients had Cheyne-Stokes respiration. In two of them 
no variations were noted in auricular or ventricular rates, while the other showed a marked slowing of the ventricular rate at the beginning of the hyperpneic period and an increase during the apneic period with no change in the auricular rate.

Many variations in ventricular and auricular complexes were noted and special attention was paid to a curious reversal of the ventricular spikes after administration of epinephrin in one case.

\section{CONCLUSIONS}

1. Evidence is presented to show that in complete heart block the accelerator nerves exert a considerable control over the ventricles whereas the vagi have only a slight influence.

2. Vagal control over the auricles is the same in complete heart block as in the normal heart.

3. Exercise in complete heart block tends to increase the auricular rate but leaves the ventricular rate unchanged.

4. Cheyne-Stokes breathing in complete heart block may be associated with varying auricular and ventricular responses.

5. A case is reported where the injection of epinephrin caused a complete change in direction of the ventricular complexes.

\section{REPORT OF CASES}

Case 1. J. L., a laborer, aged 56, was admitted to the Fourth Division medical service on August 23,1923, complaining of frequent dizzy spells and increasing weakness. He was entirely well up to six days before admission when he began to have two to three fainting attacks per day, associated with loss of consciousness and marked weakness. The frequency of these attacks increased so that at the time of admission he had about twenty a day. He was found to be dyspneic, orthopneic, cyanotic, with dilated jugular veins but no oedema. The examination of the chest was negative. The heart showed a moderate enlargement, a systolic blow at the apex, auricular sounds in the diastolic period, and a ventricular rate of 38 per minute. It was found that whenever the ventricular rate dropped to about 12 per minute, the patient would have a period of unconsciousness and convulsions. At one time a ventricular rate of 8 per minute with a ventricular standstill of 16 seconds was noted. Epinephrin was given to this patient as a therapeutic procedure because it was found to materially lessen the convulsions. The patient died on September 12, 1923, in a "status epilepticus." 
Case 2. G. S., a watchman, aged 69, was admitted to the Second Division medical service on January 23, 1923, complaining of shortness of breath. He stated that he had had "heart trouble" for over fifteen years but was able to do his ordinary work until three years ago when he began to have sudden attacks of shortness of breath bearing no constant relationship to exertion. At the time of admission to the hospital he was unable to go about, the slightest exertion causing dyspnea. There were occasional attacks of dizziness but no loss of consciousness. He was found to have no dyspnea when at rest; no signs of congestive heart failure. His chest was moderately emphysematous. Examination of the heart showed a moderate enlargement, distant sounds, no murmurs, and a ventricular rate of 30 per minute. It was noted that the jugular pulse showed faint wavelets asynchronous with the ventricular beats. On February 6, 1923, the patient had a period of semi-consciousness with a few tremors of the extremities. The heart rate at that time was 10 per minute. After that several periods of unconsciousness with convulsions occurred daily. He was discharged on March 29, 1923. On October 2, 1923, he was again admitted following an attack of dizziness and unconsciousness, during which he had failen. His physical condition was practically the same as on the previous admission. He was again discharged November 2, 1923.

Case 3. A. L., a barber, aged 73, was admitted to the Second Division medical service on December 11, 1923, in marked failure with Cheyne-Stokes breathing. It was impossible to obtain any history other than that his illness had begun about one year before with shortness of breath. He was very dyspneic, orthopneic, with marked cyanosis of all extremities. There was no oedema, although, the jugular veins were engorged and filled from below. The heart was moderately enlarged, the sounds were not very clear, but a loud high pitched systolic murmur was heard over the entire precordium. The urine showed a marked amount of albumen. He became steadily worse and died on December 15, 1923.

Case 4. W. M., a floor polisher, aged 58, was admitted to the Third Medical Division on July 7, 1923, complaining of shortness of breath and dizzy spells followed by short periods of unconsciousness. These symptoms began about February, 1923. He remained in a hospital for four weeks and was discharged improved. Just before this admission his attacks of syncope began to recur every 20 to 30 minutes. He was neither dyspneic or orthopneic. There were no signs of congestive failure. There was marked sclerosis of all the peripheral vessels. The heart was moderately enlarged, with sounds of fair quality at the apex. The rhythm was regular at times, at other times there were dropped beats every third or fourth cycle. After exercise the condition became one of complete block with long periods of asystole. He was discharged improved on August 2, 1923. In December 9, 1923, he was readmitted in coma with Cheyne-Stokes breathing and a heart rate of 60 to 85 per minute. An electıocardiogram showed complete heart block even with this rapid rate. He died on December 20, 1923. 
An autopsy showed a calcified band across the intraventricular septum, along the base of the mitral valve.

Case 5. J. L., a watchman, aged 57, was admitted to the Third Medical Division on November 16,1923, after having been found unconscious in his room a few minutes before. He regained consciousness soon after he was brought to the ward. He stated that this was his first attack, and that previous to this he had been in the best of health. He was found to be dyspneic on slight exertion, but had no congestive failure. All the peripheral arteries were markedly sclerosed. His heart was only slightly enlarged. There was a systolic murmur at the apex and also at the aortic cartiliage. The rhythm was regular, the rate being 46 per minute. He was discharged on December 1, 1923, somewhat improved.

Case 6. C. D., a housewife, aged 49, was admitted to the Third Medical Division on December 1, 1923. Her history dates back to August 1922, when she had a period of unconsciousness lasting about three minutes following unusual and severe exercise. About a month later she began to have frequent mild attacks of dizziness. In February 1923, she fell unconscious on the street without any warning, and had considerable difficulty in getting home. The next day she had a loss of consciousness with convulsions and was taken to a hospital where she remained for several weeks having frequent convulsions together with marked slowing of the pulse. Since then she has practically lived in hospitals being unable to do any work whatsoever. At rest, she presented no signs of failure. The heart was moderately enlarged, with a rough systolic murmur at the apex, sounds of good quality and a rate of 26 per minute. There were a few premature contractions. She was discharged on February 9, 1924, with very little, if any improvement.

Case 7. E. T., an embroider, aged 68, was admitted to the Third Medical Division on January 5, 1924, complaining of fainting spells, dyspnea, and palpitation. She was very unstable mentally and a reliable history could not be obtained. She had had ten to fifteen fainting spells since October 1923 and had been in bed most of the time since then. Her heart showed a slight enlargement, and a ventricular rate of 38 per minute while the jugulars pulsated at a rate of 84 per minute. The vessels were moderately sclerosed. She was discharged unimproved, January 27, 1924.

Case 8. L. M., a cobbler, aged 70, was admitted to the Second Medical Division on February 26, 1924, in coma with convulsions, after having been picked up in the street. He had a large scalp wound over the mid occipital region. There was no bleeding from the nose, ears or mouth. Neurological examination was negative. The heart was slightly enlarged to the left. The rate was 24 per minute and regular; the sounds were rather blurred; there were no murmurs. 
The pulse was of the Corrigan type. He regained consciousness for only a few days and then lapsed into a state of coma with Cheyne-Stokes breathing, which continued almost to the day of his death, March 13, 1924.

\section{BIBLIOGRAPHY}

1. Crawford: Jour. Pharm. and Exp. Ther., 1923, xxii, 1. The Influence of the Vagus on the Heart Rate.

2. Cullis, W., and Tribe, E.: Jour. Physiol., 1913, xlvi, 141. Distribution of Nerve: in the Heart.

3: Eyster, J. A. E., and Meek, W. J.: Amer. Jour. Physiol., 1922, lxi, 117. The Permanent Rhythm Following Destruction of the Sino-auricular Node.

4. Feil, H.: Jour. Amer. Med. Assoc., 1920, lxxx, 26. The Use of Epinephrin in Stokes-Adams Syndrome.

5. Hardoy, P. T., and Houssay, B. A.: Jour. de Physiol. et de Path. Gen., 1918, xvii, 605. Note sur l'Action de l'Adrenaline dans la Dissociation Auriculoventriculaire.

6. Oppenheimer and Williams: Proc. Soc. Exp. Biol. and Med., 1913, x, 86. Prolonged Complete Heart-block without Lesion of the Bundle of His and with Frequent Changes in the Idio-ventricular Electrical Complexes.

7. Sands, M. J.: Arch. Pediat., 1923, xl, 343. Heart Block in a Child of Five Years.

8. Strisower, R.: Wien. klin. Wchnschr., 1920, xxxiii, 269. Pharmokologische Beeinflussung des Pulses bei einem Fall von Herzblock.

9a. Wiggers, C. J.: Circulation in Health and Disease. Philadelphia, 1923, p. 50.

9b. Wiggers, C. J., and Katz, L. N.: Amer. Jour. Physiol., 1920, liii, 49. The Specific Influence of the Accelerator Nerves on the Duration of Ventricular Systole. 